\title{
Palliative care nurse specialists' reflections on a palliative care educational intervention in long-term care: an inductive content analysis
}

\author{
Rosemary Frey ${ }^{*}$ (D, Deborah Balmer, Michal Boyd, Jackie Robinson and Merryn Gott
}

\begin{abstract}
Background: Older people in long-term care facilities are at a greater risk of receiving care at the end of life that does not adequately meet their needs, yet staff in long-term care are often unprepared to provide palliative care. The objective of the study was to explore palliative care nurse specialists' experiences regarding the benefits of and barriers to the implementation of a palliative care educational intervention, Supportive Hospice Aged Residential Exchange (SHARE) in 20 long-term care facilities.

Methods: Reflective logs (465), recorded over the course of the yearlong SHARE intervention by the three palliative care nurse specialists from two local hospices, who were the on-site mentors, were qualitatively analyzed by two researchers utilizing inductive content analysis.

Results: Categories emerging from the logs include the importance of relationships, knowledge exchange, communication, and the challenges of providing palliative care in a long-term care setting.

Conclusion: Evidence from the logs indicated that sustained relationships between the palliative care nurse specialists and staff (registered nurses, healthcare assistants) as well as reciprocal learning were key factors supporting the implementation of this palliative care educational intervention. Challenges remain however in relation to staffing levels, which further emphasizes the importance of palliative care nurse specialist presence as a point of stability.
\end{abstract}

Keywords: Palliative, Long-term care, Educational intervention, Hospice

\section{Background}

As populations age, "home" at the time of death for a growing number of older people will be long-term care facilities [1]. In addition, older people in long-term care are more likely to live with complex co-morbidities and experience illness within the context of existing physical or mental impairment $[2,3]$. As one of the most disadvantaged and vulnerable groups in industrial societies, older people in long-term care facilities are thus at a greater risk of receiving care at the end of life that does not adequately meet their needs [4]. The increasingly complex needs of long term care residents and the fact that a large number

\footnotetext{
* Correspondence: r.frey@auckland.ac.nz

School of Nursing, Faculty of Medical and Health Sciences University of Auckland, 85 Park Road, Grafton, Auckland, New Zealand
}

of older adults will die while long-term care makes it essential that services have processes in place to facilitate quality palliative and end of life care. Long-term care in New Zealand is synonymous with residential aged care. The level of care provided is based on need and includes rest home care (support but not $24 \mathrm{~h}$ nursing/medical care), hospital-level care (24-h nursing/medical care), dementia care and psychogeriatric care [5].

The New Zealand Health Needs Assessment for Palliative Care conducted under the auspices of the Palliative Care Council concluded that almost all long-term care facility residents would require palliative care at the end of their life [6]. Furthermore, 50\% would benefit from specialist palliative care advice and support, while the other $47 \%$ could be managed by the long-term care

(c) The Author(s). 2019 Open Access This article is distributed under the terms of the Creative Commons Attribution 4.0 International License (http://creativecommons.org/licenses/by/4.0/), which permits unrestricted use, distribution, and 
facility, given the capabilities and resources to provide a generalist level of palliative care [7].

Within the context of this study, long-term care staff refers to registered nurses and health care assistants (non-health professional support workers) directly involved in the care of residents.

Research has indicated that registered nurses in longterm care facilities are often unprepared to provide palliative care [8]. For example, they feel ill-equipped to undertake Advance Care Planning (ACP), [9] a process of discussion and shared planning for future health care that assists the individual to identify their personal beliefs and values and incorporate them into plans for their future health care [10]. There is also evidence that longterm care facility staff (both registered nurses and health care assistants) feel inadequately supported in coping with multiple bereavement experiences [11]. Addressing the palliative care knowledge and skills deficit, as well as the emotional readiness of long-term care facility staff is therefore of critical importance to delivering quality palliative care $[7,12,13]$.

However, a major challenge continues to be the translation of educational interventions to the reality of the long-term care environment [14]. The negative impact of burnout on education uptake and the lack of consideration of organisational factors (e.g. low staffing levels, time pressures) may present obstacles to sustainable change $[15,16]$. Furthermore, conflicts may arise between hospice as an organization and long-term care facilities hindering the delivery of quality care [17]. The provision of complex, quality health care requires effective relationships among multidisciplinary team members, as well as the ability to learn together and adapt to change [18-21].

Education initiatives developed to date have focused on short training programs concentrating on the traditional "chalk and talk" format [22, 23]. However, there is minimal evidence that nurse and support staff knowledge gained from this format is sustained in the long term [14]. Adults learn best from direct experience [24]. As quoted from Confucius "Tell me, and I will forget. Show me, and I may remember. Involve me, and I will understand." It is within this context that the need for a new model of education delivery has been identified that supports "handson" learning which is a vital component of the sustained transfer of new knowledge into practice [25].

The Supportive Hospice Aged Residential Exchange (SHARE) intervention provides a means to package and systematically support knowledge exchange between hospice palliative care nurse specialists and long-term care facility direct care staff (registered nurses, health care assistants). Hospice palliative care nurse specialists are defined as registered nurses with a recognized palliative care qualification [26] Although hospice involves in-patient services, hospice palliative care nurse specialists also provide care in the community including to residential aged care residents [27]. The goal of SHARE is to improve palliative care delivery [28]. Palliative care in this paper is defined as an approach to care that improves the quality of life of patients and their families for those facing a life-threatening illness [29]. It involves care across the duration of the resident's illness [29]. End-of-life care is incorporated into palliative care, although the timeframe differs in that it is typically limited to the last few months of life [30]. SHARE implementation involved weekly visits by one of three palliative care nurse specialists from two local hospices to twenty local long-term care facilities.

SHARE components. The SHARE model included: 1) a records review and assessment of the goals of care of residents identified as having palliative care needs by the palliative care nurse specialist and facility $\mathrm{RN}$, using the Clinical Frailty scale [31] and Supportive Palliative Care Indicators Tool [32]; 2) palliative care nurse specialist and RN reciprocal clinical coaching; 3) role modelling of advance care planning conversations with RN's; 4) palliative care education planning and 5) debriefing following a resident death with the facility RN's, and to a lesser degree with HCA's [28]. Evidence indicates that these methods can achieve sustained knowledge transfer [32-34]. (Table 1). SHARE was implemented and evaluated in 20 long-term care facilities, for 1 year in two district health boards. Each palliative care nurse specialist was assigned a subset of the 20 facilities to visit weekly.

The goal of the larger SHARE evaluation was to determine if the intervention was contextually appropriate and sustainable. This study forms Phase One of the larger SHARE evaluation and explores the palliative care nurse specialists' views and experiences regarding the benefits and barriers to SHARE implementation in longterm care facilities. The effective implementation of any educational intervention is dependent on the perceptions and interpretations that both mentors and students bring to the encounter [33]. While there are studies focusing on the impact of palliative care interventions on residents, clinical staff and families [34-37] little research has dealt with the perceptions of the facilitators [38]. An individual's perceptions of experience directly influence their subsequent motivation [39]. It would seem important that the perceptions of the palliative care nurse specialists delivering SHARE be examined.

\section{Methods}

The objective of the study was to explore hospice nurses' views and experiences regarding the barriers and facilitators to the implementation of a palliative care educational intervention (SHARE) in long-term care facilities. The study forms part of a larger yearlong mixed-methods evaluation of SHARE in 20 long-term care facilities. 
Table 1 Components of the SHARE model (Frey et al., 2017)

\begin{abstract}
Records Review
The identification of residents who would benefit from a palliative approach was completed through a records review conducted by the hospice palliative care nurse specialist in conjunction with a registered nurse (RN) from each facility. The review included an assessment of resident palliative care need using the Supportive Palliative Care Indicators Tool [31] and the Clinical Frailty Scale [32]. The purpose of the review was to provide the basis for ongoing monitoring of resident palliative care need and to create a "Goals of Care" plan for those on the registry.

Clinical Coaching and Role Modelling
\end{abstract}

This was a reciprocal process of shared learning between palliative care nurse specialists and long-term care RN's and healthcare assistants (HCA's). In partnership with HCA's, RN's and General Practitioners (GP) the palliative care nurse specialists worked to develop and update a "Goals of Care" plan to reflect new or changing palliative care needs. This consultation was made in partnership with the RN and HCA present to provide opportunities for clinical coaching, role modelling and development of clinical knowledge.

Palliative Care Education Planning

The palliative care nurse specialist worked together with RN's and HCA's to discuss the specific learning needs in each facility identifying the priorities for staff. A programme of education was be developed that was unique to that facility and complimented the current education provided by the two hospices.

Debriefing

Debriefing following resident deaths was offered facilitated by the palliative care nurse specialist in collaboration with a senior RN from the facility. This service provided an opportunity to acknowledge the emotional impact of end of life care. It also provided an opportunity to reflect on the care provided.

\section{Participants}

All of the palliative care nurse specialists were female and between 40 and 55 years of age. One palliative care nurse specialist had between five and 9 years of experience in the field while the other two had over 10 years' experience in palliative care. Two of the palliative care nurse specialists had less than 5 years' experience working with long-term care while one had over 20 years working with the sector. Given the small number of contributors, identifiers for quotes (log ID and facility identification) have been omitted to maintain the confidentiality of both the palliative care nurse specialists and the facilities.

\section{Process}

The extensive reflective logs, recorded over the course of the yearlong SHARE intervention by the three palliative care nurse specialists, who were the on-site mentors, were qualitatively analyzed. The palliative care nurse specialists were asked to keep a weekly journal for each of the 20 facilities. The journals included sections on resident care as well as a section for reflective comments about their perceptions of how the intervention protocol supported the goal of improving palliative care knowledge among staff in long-term care facilities. Journals were selected as the most appropriate method for capturing a personal indepth perspective on a day to day basis [40]. Their contemporaneous nature makes journals less subject to the effects of context and recall biases than other data collection methods such as interviews [41]. Ross et al. [42] in exploring the use of diaries (journals) by nurses concluded that this tool was a "trustworthy and effective method of data collection (p. 417)' This report focusses on the reflective section. Four hundred sixty-five reports (average of $23 /$ facility) were submitted by the palliative care nurse specialists over the 1 year of SHARE implementation. All data collection took place between September 2017 and November 2018. The start of SHARE in facilities was staggered across the period. Significant information obtained from the journals included palliative care nurse perceptions of improved registered nurse communication with families, improved registered nurse identification of residents with palliative care needs, palliative care nurse specialist gains in knowledge in gerontology and dementia care.

\section{Analysis}

All logs were imported into QSR NVivo 12 for analysis. The process of inductive content analysis was utilized [43]. The researchers (RF, DB) read all logs several times. Open coding headings were used to describe all aspects of the content. Headings were listed on a coding sheet and categories were created. Following open coding, the categories were grouped together into higherorder headings by combining categories with similar content. Higher-order headings were refined as the analysis process progressed through in-depth discussions between DB and RF. The names of the categories were selected based on their ability to represent the overall sense of the logs. Subcategories were identified through the process of abstraction.

\section{Results}

Four categories were isolated. Three categories reflected the benefits of SHARE (relationships), knowledge exchange, communication), while barriers to SHARE are reflected under the category challenges. Categories and subcategories are portrayed in Fig. 1.

\section{Relationships}

A common topic from all the logs was the building of relationships - of facility staff with residents, and with families, connections among facility staff, and in the case of the hospice nurses, the importance of building a strong connection with the facility staff in order to build trust. 


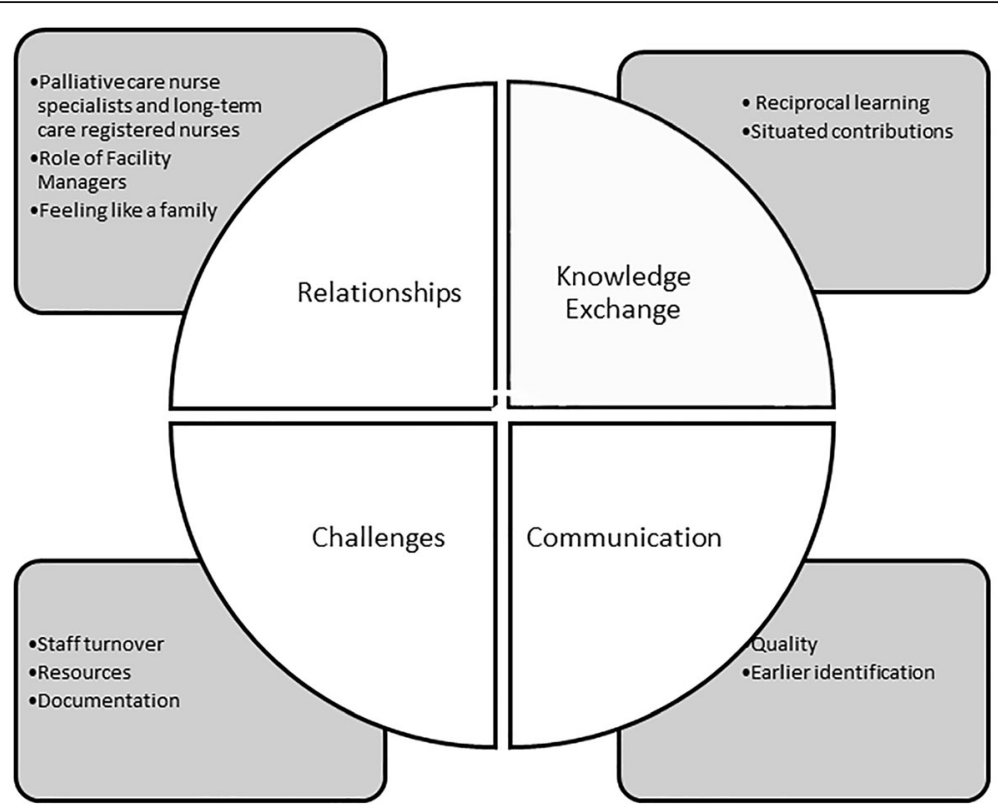

Fig. 1 Categories and sub-categories identified within the log texts

\section{Palliative care nurse specialists and long-term care registered nurses}

The establishment of relationships between the palliative care nurse specialists and long-term care facility registered nurses, helped develop a sense of both trust and understanding of the role and scope of hospice in the care of residents.

\section{SHARE helped the long-term care facility team and myself developing a better rapport. Particularly in my relationship with care staff, they would share with me about their wedding anniversaries and family's strug- gles. I sensed that there was added meaning to their work somehow.}

The following quote highlights the need for the reinforcement and support provided by the palliative care nurse specialist as illustrated by this example of the isolation within which facility registered nurses often work.

Long-term care facility nurse was working in such a lonely environment. I could see the joy in the eyes of RN's [registered nurses] [name] and [name] when I listened to them. When I gave RN [name] my honest praise about her kindness and compassionate care to her elderly resident, she actually had tears. She was very humbled and said, "I was doing my job. I thought I was doing what everyone does!" Such beautiful and caring nurses!

\section{Role of facility managers}

Support for SHARE on the part of facility managers fostered closer relationships between registered nurses, health care assistants, and managers. The strengthened relationship managers, in turn, facilitated greater collaboration with the palliative care nurse specialists:

One [health care assistant] in particular whom I found to be very prickly when I first started visiting [facility] and how her demeanor had changed over the last 12 months. When I walked in today, I could hear her laughing and joking with the staff and she even came up and gave me a hug. I put that down to the way that [manager] has been managing and supporting the staff and the improvements she has made within the facility.

\section{Feeling like a family}

Opportunities for participation in activities encouraged socialization between facility staff members (RN's, HCA's) and between staff and residents. These activities provided a mutual feeling of "family" that fostered the development of collaborative relationships, a key prerequisite for SHARE success.

It was clear which facility did want to involve residents 'family.' When Nurse Manager A announced Christmas decoration competition in individual Suites, I could hear that the focus was on the dignity of residents ... Looking at the staff involvement in their own party and the trolley filled with Secret Santa, I felt this place was full of love...If staff were not happy, they wouldn't bother to participate in Secret Santa or Share lunch. 


\section{Knowledge exchange \\ Reciprocal learning}

The sharing of palliative care knowledge and applied between the hospice nurses and the long-term care facility staff and growth in hospice nurses' understanding of geriatric care was evident in the logs. The hospice nurses' perspectives on care in long-term care facilities revealed new understandings of geriatric care and the palliative care trajectory of chronic illness with all of its uncertainty.

The learning from SHARE discussions with [name] [RN] has been most beneficial to inform my knowledge to a broader level of the "strength of the human spirit to survive when the body and mind are dying" especially with reference to those who have dementia and advanced frailty.

\section{Situated contributions}

There is considerable evidence of situated interventions by the hospice nurse where the hospice nurses' deliberate presence in the long-term care facility created plentiful moments where discussion, learning, teaching, and changes in practice took place.

It was quite rewarding to see $R N$ [name] come up with the resident for Palliative Care Register. This RN team worked quietly and never showed any excitement on the SHARE visit. Thus, when they voluntarily gave me a name "[Hospice Nurse], I think this resident was ready for a palliative care approach ..." I was quietly joyful. Without SHARE, this facility had not been offered palliative care education in the past and (a hospice) community team had not been in touch for at least 2 years.

Other insights for the hospice nurse indicated areas for further education. This was particularly true in regard to maintaining ongoing communication with families about changes in their relative's condition and care needs.

I was surprised that the predominance of residents reviewed was by default as" For Resus" [resuscitation] ... RN/facility under the impression of the resident is unable to cognitively decide rendered them as 'resuscitatable' rather than working with the family as part of ACP [advance care planning] process.

\section{Communication}

\section{Quality}

Registered nurse confidence in communication skills with regard to palliative and end of life care as well as the ability to initiate advance care planning with families improved in some facilities. One hospice nurse reflected on both the improved palliative care knowledge and communication skills of a registered nurse:

The long-term care facility team had been very caring for him [resident] and kept close communication with him [resident] and his son. RN [name] was able to share with me that the resident [name] and his son discussed funeral arrangements in the last $48 \mathrm{~h}$. She felt particularly proud of able to recognise dying and facilitate communication amongst resident and his son.

\section{Early palliative care needs identification}

The logs also provided evidence of better documentation of residents with palliative care needs. Better identification allows for proactive care planning before the terminal stage.

When I was preparing for the resident's information for a research report, I realised that all recent deceased residents were enrolled onto Palliative Care Register.

\section{Challenges}

Key themes reflected throughout the logs included the detrimental effects of resource constraints and increasing staff turnovers. These factors not only influence palliative care education and delivery but also staff well-being.

\section{Staff turnover, \& under-resourcing}

The level of reference to staff turnover, insufficient staffing \& staff changes (especially RNs coming in from overseas who use the long-term care sector to bridge into work in district health boards) is troubling. This, in turn, led to very challenging circumstances in which to provide staff education in a traditional classroom sense, making the physical presence of the hospice nurses even more significant in sharing knowledge and practice between the long-term care facilities and the hospice nurses.

The lead clinical nurse in the Dementia Unit has left. Find this unfortunate as she appeared to us to be very knowledgeable in the care of those with dementia.

They do not have someone to replace her as yet.

The continuing staff shortages serve as a further indicator of the need for an alternative to traditional didactic methods of teaching. Staff shortages translate into a lack 
of staff available to attend sessions, as indicated in the following reflection:

\section{Even CCM [clinical charge nurse manager] A could honestly share that she was constantly orientating a new group of nurses. They were not in any shape to take on [education] training at all.}

\section{Documentation}

Problems persisted in some facilities particularly in relation to future care documentation. The palliative care nurse specialists in the SHARE study documented practices that they found troubling concerning palliative care and especially unnecessary hospital admission.

A new nurse was on duty and there were no clear easy to access guidelines in residents' notes about her future plan of care. Therefore, by default, she went to the hospital where she spent $24 \mathrm{~h}$, was commenced on oral antibiotics and then returned to the facility.

\section{Discussion}

A number of factors supported the educational intervention, Supportive Hospice Aged Residential Exchange (SHARE) as perceived by the three hospice nurses. In the first instance, the relationship that the palliative care nurse specialists forged with facility registered nurses, health care assistants as well as facility managers appeared to have a huge bearing on the success of the uptake of the learning. Developing a connection and acceptance of the specialist nurse specialist was key i.e. that the palliative care nurse specialist needed this relationship to be developed in order to feel her role was effective. Indeed, previous research has indicated a relationship between improved student outcomes and the development of a trusting teacher-student relationship [44]. Having a dedicated palliative care nurse specialist visiting on-site regularly allowed the registered nurses to build a key relationship, encouraging them to share the gaps in their knowledge, as well as to ask for support in working with families. Comments on the personal support that the palliative care nurse specialist gave indicate that along with providing specialist palliative care knowledge, they became a source of comfort for many stressed registered nurses. Trust has also been associated with increased sharing and collaboration [45]. In fact, trust and collaboration reinforce each other [45]. Ongoing contact between the parties (in this instance, palliative care nurse specialists, registered nurses and health care assistants), creates the opportunity to increased trust, leading to enhanced motivation to learn [46]. This increased motivation, in turn, supports a willingness for continued collaboration. In other words, with ongoing contact, the palliative care nurse specialist gained acceptance within the facilities and was in turn welcomed as part of the "staff family". The development of a trusting relationship where registered nurses felt "safe" to ask for help with caring for residents with palliative care needs was a key component of the SHARE model. Relationships between staff (RN's, HCA's) and facility managers were also key to palliative care nurse specialists' perceptions of improved resident and family care. Previous research has indicated that the quality of the relationships and communication among staff members is a key predictor of health care quality [47].

Drawing on Lave and Wenger [48], learning within long-term care facilities is a situated and collaborative activity, a process of participation in "communities of practice." Learning is context-bound, shaped by the sociocultural practices of the organization. Indeed, research indicates that setting, activities, and artifacts also play a key role in learning, particularly in tasks that require higher-order knowledge [49]. According to Billet [49], "the adaptability of the knowledge that has been learned is premised upon its discernible applicability to particular situations" (p. 389). Findings also point to evidence of reciprocal learning with palliative care nurse specialists gaining new knowledge and understanding during the interactions with registered nurses and health care assistants.

Previous research has indicated that mentoring is linked to personal and professional development for mentors [50]. Palliative care nurse specialist mentors appeared to have expanded their knowledge of gerontology as well as their understanding of long-term care registered nurse perspectives [51]. In essence, the palliative care nurse specialists and the registered nurses in the long-term care facilities developed a peer-learning partnership - a reciprocal learning relationship between parties of equal status who share a common goal [52]. Findings indicated that interactions as part of the SHARE role increased the palliative care nurse specialists' respect for the care provided by the facility as well as their own knowledge and skill to care for frail older people. The partnership thus facilitated knowledge exchange between the palliative care nurse specialists and registered nurses and health care assistants with the goal of improving palliative care delivery within the longterm care facilities. This, in turn, helped to establish a trusting relationship built on mutual respect [53].

Evidence from the hospice logs indicated both a recognition of improved communication about changes in a resident's condition with family members. Excellent palliative care occurs when interdisciplinary team members communicate effectively and collaborate on care plans [34]. Therefore, it is 
necessary for all health care providers (including health care assistants) to become more effective at interpersonal communication and collaborative skills [54]. Mentoring by palliative care nurse specialists appears to have enhanced interpersonal communication skills for registered nurses. Barriers to communication persisted, however, particularly in relation to the initiation and documentation of advance care plans for residents. There is a significant relationship between advance care plans and quality of dying [55] as well as a relationship between the care received at end of life and patient preferences [56]. As in previous research, lack of willingness to document palliative care need may stem from prior uneasiness with discussing advance care plan related issues with residents or families [57].

The level of reference to staff turnover, insufficient staffing, and staff changes was highlighted by hospice nurses and represented a barrier to SHARE implementation. Low staffing levels and the associated time pressures can create barriers to the uptake and application of new knowledge [58]. Previous research has indicated a staff preference for interactive, hands-on, applied learning [59] making the physical presence of the palliative care nurse specialists even more significant in sharing knowledge and practice. Furthermore, traditional training and education methods in palliative and end of life care have previously required registered nurses to leave the clinical environment to attend study days and training sessions [60] creating more staffing pressures for long-term care facilities. In contrast, SHARE does not pull registered nurses away from the bedside and therefore does not require "more time" to attend teaching sessions. Nevertheless, the continued staff turnovers presented a challenge to the establishment of trusting relationships between the palliative care nurse specialists and new staff registered nurses. Such challenges require the development of skills on the part of palliative care nurse specialists to create genuine connections, even in brief encounters. Such skills can result in greater trust and opportunities for teamwork to develop [61].

\section{Strengths and limitations}

The findings and consequent discussion are based solely on the perceptions and observations of the hospice nurses. The views and opinions of others involved in the evaluation, such as the long-term care facility registered nurses, managers, and residents, have not been included. However, because the logs were maintained over the course of a year, emerging patterns were revealed which may not have been observable with other methods. Furthermore, both contextual and recall biases were significantly reduced as logs were created as events unfolded [62].

\section{Conclusion}

The overall impression of the palliative care nurse specialists was that SHARE supports the building of a strong relationship between the hospice nurse specialists and facilities, facilitates improved communication between registered nurses and residents and registered nurses and families and alerts registered nurses to be vigilant in assessing the palliative care needs of their residents. Furthermore, evidence from the logs indicated that the more the palliative care nurse specialists interacted with long-term care registered nurses and health care assistants, the better the knowledge base for both sides. Role modeling of difficult conversations with families may build confidence in the long-term care registered nurses to begin advance care planning conversations earlier as well as improve ACP documentation. Barriers to SHARE implementation remain however in relation to long-term care staffing levels and staff turnover. Ultimately, continued implementation of SHARE and the form of that implementation are dependent on both resourcing and the commitment of all parties involved. However, the hospices, district health boards and long-term care decision-makers are committed to ensuring effective and timely knowledge transfer from evidence gathered in this study into policy and practice within long-term care.

\section{Abbreviations \\ ACP: Advance care planning; CCM: Clinical charge nurse manager; \\ HCA: Healthcare assistant; RN: Registered nurse; SHARE: Supportive Hospice Aged Residential Exchange}

\section{Acknowledgements}

We would like to thank all the long-term care facilities and staff who took part in this study.

\section{Author's contribution}

$R F, D B, M B, J R$, and $M G$ were involved in the conception, design, and implementation of the research. RF, DB, were involved in the data analysis and interpretation, and $R F, D B, M B, J R$, and $M G$ were involved in the drafting of the paper. $R F, D B, M B, J R$, and $M G$ were involved in the review and approval of the final article for publication.

\section{Funding}

This study was supported by funds of the Freemasons Foundation (Project Number 3713302) and the Health Research Council (Contract \#:16/813). The funding sources had no role in the study design; data collection, analysis, or interpretation of the data or writing of the report.

\section{Availability of data and materials}

The dataset used and/or analysed during the current study are available from the corresponding author on reasonable request in a de-identified form.

Ethics approval and consent to participate

Ethical approval for this component of the larger evaluation was obtained from the University of Auckland Human Participants Ethics Committee (ref. 020075). Written informed consent was obtained from all participants. 


\section{Consent for publication}

Not applicable.

\section{Competing interests}

The authors declare that they have no competing interests.

Received: 5 June 2019 Accepted: 12 November 2019

\section{Published online: 19 November 2019}

\section{References}

1. Gomes B, Higginson IJ. Where people die (1974-2030): past trends, future projections and implications for care. Palliat Med. 2008;22(1):33-41.

2. Davies E, Higginson IJ. Better palliative care for older people. Regional Office for Europe Copenhagen: world health Organization; 2004.

3. Seymour J, Witherspoon R, Gott M, Ross H, Payne S. T O. end-of-life care: promoting comfort, choice and well-being for older people. Bristol: Policy Press; 2005.

4. Hermann CP, Looney SW. Determinants of quality of life in patients near the end of life; a longitudinal perspective. Oncol Nurs Forum. 2011;38(1):23-31.

5. New Zealand Legislation. Health and Disability Services (Safety) Act 2001 [Internet]. Wellington: New Zealand Government; 2001. Available from: http://www.legislation.govt.nz/act/public/2001/0093/latest/DLM119975.html

6. Palliative Care Council of New Zealand. National health needs assessment for palliative care. Wellington: Cancer Control New Zealand; 2011.

7. Naylor W. National health needs assessment for palliative care. Phase report, assessment of palliative care need [electronic resource]. Palliative Care Council of New Zealand: Wellington; 2011.

8. Marshall B, Clark J, Sheward K, Allan S. Staff perceptions of end-of-life care in aged residential care: a New Zealand perspective. J Palliat Med. 2011;14(6): 688-95.

9. Silvester W, Fullam R, Parslow R, Lewis V, Sjanta R, Jackson L, et al. Quality of advance care planning policy and practice in residential aged care facilities in Australia. BMJ Support Palliat Care. 2012;3(3):349-57.

10. Ministry of Health (New Zealand). Advance Care Planning: A guide for the New Zealand healthcare workforce. Wellington: Ministry of Health; $2011 \mathrm{~b}$ [cited 201510 March]. Available from: http://www.health.govt.nz/our-work/ life-stages/palliative-care

11. Freyer S. Caring for imminently dying residents in aged care facilities: the experiences of health care assistants in NZ. Auckland: University of Auckland; 2013

12. Hunter P, McCleary L, Akhtar-Danesh N, Goodridge D. Haadjistavropoulos T, Kaasalainen S, et al. Mind the gap: is the Canadian workforce ready for a palliative mandate? Ageing Soc. 2019;(online). https://doi.org/10.1017/ S0144686X18001629.

13. Strumpf N, Tuch H, Stillman D, Parrish P, Morrison N. Implementing palliative care in the nursing home. Ann Long-Term Care. 2004;12(11):35-41.

14. Aylward S, Stolee P, Keat N, Johncox V. Effectiveness of continuing education in long-term care: a literature review. Gerontologist. 2003;43(2): 259-71.

15. Frey R, Boyd M, Foster S, Robinson J, Gott M. Burnout matters: the impact on residential aged care staffs' willingness to undertake formal palliative care training. Prog Palliat Care. 2015;23(2):68-74.

16. Frey R, Boyd M, Foster S, Robinson J, Gott M. What's the diagnosis? Organisational culture and palliative care delivery in residential aged care in New Zealand. Health Soc Care Community. 2015;24(4):450-62.

17. Miller S, Teno J, Mor V. Hospice and palliative care in nursing homes. Clin Geriatr Med. 2004;20(4):717-34.

18. Crabtree BF, Nutting PA, Miller WL, McDaniel RR, Stange $K C$, Jaen $C R$, et al. Primary care practice transformation is hard work: insights from a 15-year developmental program of research. Med Care. 2011;49(Suppl):S28-35.

19. Jordan ME, Lanham HJ, Crabtree BF, Nutting PA, Miller WL, Stange KC, et al. The role of conversation in health care interventions: enabling sensemaking and learning. Implement Sci. 2009;4:15.

20. Lanham HJ, McDaniel RR Jr, Crabtree BF, Miller WL, Stange KC, Tallia AF, et al. How improving practice relationships among clinicians and nonclinicians can improve quality in primary care. Jt Comm J Qual Patient Saf. 2009;35(9):457-66.

21. Nutting PA, Crabtree BF, Miller WL, Stange KC, Stewart E, Jaen C. Transforming physician practices to patient-centered medical homes: lessons from the national demonstration project. Policy Anal Brief H Ser. 2011;30(3):439-45
22. Quinn K, Hudson P, Ashby M, Thomas K. Palliative care: The essentials: Evaluation of a multidisciplinary education program. Palliat Med. 2008;11(8): 1122-9.

23. Raunkiaer $\mathrm{M}$, Timm H. Interventions concerning competence building in community palliative care services-a literature review. Scand J Caring Sci. 2013;27(4):804-19.

24. Kolb D. Experiential learning: experience as the source of learning and development. Pearson: Upper Saddle River, NJ; 2014

25. Taylor M. Transfer of learning in workplace literacy programs. Adult Basic Educ Lit J. 2000;10(1):3-20.

26. $\mathrm{MOH}$. The New Zealand palliative care strategy. Wellington: Ministry of Health; 2001.

27. MacLeod R, Thompson R, ., Fisher J, Mayo K. New Zealanders' knowledge of palliative care and hospice services. N Z Med J 2012;125(1348):51-60.

28. Frey R, Boyd M, Robinson J, Foster S, Gott M. The supportive hospice and aged residential exchange (SHARE) programme in New Zealand. Nurse Educ Pract. 2017:25:80-8.

29. Ministry of Health (New Zealand) Palliative care; a working definition. NZ Government: Wellington; 2011.

30. Reid C, Gibbins J, McCoubrie R, Forbes K. Palliative care is not same as end of life care. BMJ. 2011;342:d2735.

31. Rockwood K, Song X, MacKnight C, Bergman H, Hogan D, McDowell I, et al. A global clinical measure of fitness and frailty in elderly people. Can Med Assoc J. 2005;173(5):489-95.

32. Highet G, Crawford D, Murray SA, Boyd K. Development and evaluation of the Supportive and Palliative Care Indicators Tool (SPICT): a mixed-methods study. BMJ Support \& Palliat Care. 2014;4(3):285-90.

33. Lake $S$, Mclnnes R. Exploring cognitive skill development in midwifery education. Nurse Educ Pract. 2012;12(5):264-8.

34. Phillips J, Davidson P, Jackson D, Kristjanson L. Multi-faceted palliative care intervention: aged care nurses' and care assistants' perceptions and experiences. J Adv Nurs. 2008;62(2):216-27.

35. Badger F, Clifford C, Hewison A, Thomas K. An evaluation of the implementation of a programme to improve end-of-life care in nursing homes. Palliat Med. 2009;23(6):502-11.

36. Arcand M, Monette J, Monette M, Sourial N, Fournier L, Gore B, et al. Educating nursing home staff about the progression of dementia and the comfort care option: impact on family satisfaction with end-of-life care. J Am Med Dir Assoc. 2009;10(1):50-5

37. Volicer L, Collard A, Hurley A, Bishop C, Kern D, Karon S. Impact of special care unit for patients with advanced Alzheimer's disease on Patients' discomfort and costs. J Am Geriatr Soc. 1994;42(6):597-603.

38. O'Brien M, Kirton J, Knighting $K$, Roe B, Jack B. Improving end of life care in care homes; an evaluation of the six steps to success programme. BMC Palliat Care. 2016;15(1):53.

39. Kelly G. The psychology of personal constructs: a theory of personality vol 1. New York: Norton and Company; 1955.

40. Bedwell C, McGowan L, Lavender T. Using diaries to explore midwives' experiences in intrapartum care: an evaluation of the method in a phenomenological study. Midwifery. 2012;28(2):150-5.

41. Snowden M. Use of diaries in research. Nurs Stand. 2015:29(44):36.

42. Ross M, Rideout E, Carson M. The use of the diary as a data collection technique. West J Nurs Res. 1994;16(4):414-25.

43. Elo S, Kyngäs H. The qualitative content analysis process. J Adv Nurs. 2008; 62(1):107-15.

44. Bryk A, Schneider B. Trust in schools: a core resource for improvement. Russell Sage Foundation: New York, NY; 2002.

45. Baran M. Teaching the adult learner: building trust and motivation. In: Outcome-based strategies for adult learning. PA: IGI Global; 2019. p. 12-33.

46. Ennen N, Stark E, Lassiter A. The importance of trust for satisfaction, motivation, and academic performance in student learning groups. Soc Psychol Educ. 2015;18(3):615-33.

47. Anderson R, Ammarell N, Bailey D Jr, Colón-Emeric C, Corazzini K, Lillie M, et al. Nurse assistant mental models, sensemaking, care actions, and consequences for nursing home residents. Qual Health Res. 2005;15(8): 1006-21.

48. Lave J, Wenger E. Situated learning: legitimate peripheral participation. Cambridge: Cambridge university press; 1991.

49. Billet S. Authenticity in learning activities and settings In N. Seel (ed.). Encyclopedia Sci Learn. 2012:388-91. https://doi.org/10.1007/978-1-4419$1428-6$ 
50. de Tormes EL, Brown L, George K. Mentoring as a strategy for facilitating learning: Protégé and mentor perspectives. In: International handbook of research in professional and practice-based learning. In: Springer; 2014. p. 1071-97.

51. Eby L, Lockwood A. Protégés' and mentors' reactions to participating in formal mentoring programs: a qualitative investigation. J Vocat Behav. 2005; 67(3):441-58.

52. Eisen M. Peer learning partnerships: promoting reflective practice through reciprocal learning. Inquiry. 2000;19(3):5-19.

53. Ruth-Sahd L. Student nurse dyads create a community of learning: proposing a holistic clinical education theory. J Adv Nurs. 2011;67(11):2445-54.

54. Friesen L, Andersen E. Outcomes of collaborative and interdisciplinary palliative education for health care assistants: a qualitative metasummary. J Nurs Manag. 2019;27(3):461-81.

55. Vandervoort A, Houttekier D, Vander Stichele R, van der Steen JT, Van den Block L. Quality of dying in nursing home residents dying with dementia: does advanced care planning matter? A nationwide postmortem study. PLoS One. 2014;9(3):e91130.

56. Silveira M, Kim S, Langa K. Advance directives and outcomes of surrogate decision making before death. N Engl J Med. 2010;362(13):1211-8.

57. Froggatt $K$, Vaughan S, Bernard C, Wild D. Advance care planning in care homes for older people: an English perspective. Palliat Med. 2009;23(4):332-8.

58. Latta LE, Ross J. Exploring the impact of palliative care education for care assistants employed in residential aged care facilities in Otago. New Zealand Sites. 2010;7(2):30-52.

59. Frey R, Boyd M, Foster S, Robinson J, Gott M. Necessary but not yet sufficient: a survey of aged residential care staff perceptions of palliative care communication, education and delivery. BMJ Support \& Palliat Care 2016;6(4):465-73.

60. Henning M, Hu J, Webster C, Brown H, Murphy J. An evaluation of hospice New Zealand's interprofessional fundamentals of palliative care program at a single site. Palliat Support Care. 2015;13(03):725-32.

61. McDonald G, Vickers MH, Mohan S, Wilkes L, Jackson D. Workplace conversations: building and maintaining collaborative capital. Contemp Nurse. 2010;36(1/2):96-105.

62. Bartlett R. Modifying the diary interview method to research the lives of people with dementia. Qual Health Res. 2012;22(12):1717-26.

\section{Publisher's Note}

Springer Nature remains neutral with regard to jurisdictional claims in published maps and institutional affiliations.

Ready to submit your research? Choose BMC and benefit from:

- fast, convenient online submission

- thorough peer review by experienced researchers in your field

- rapid publication on acceptance

- support for research data, including large and complex data types

- gold Open Access which fosters wider collaboration and increased citations

- maximum visibility for your research: over $100 \mathrm{M}$ website views per year

At $\mathrm{BMC}$, research is always in progress.

Learn more biomedcentral.com/submissions 